\title{
Structural evolution and wear properties of the laser melted deposited nanocrystalline composites on TA7
}

\author{
Q.-Y. $\mathrm{Ma}^{1,2}$, X. Gao ${ }^{1}$, J.-Q. $\mathrm{Li}^{1,2 *}$ \\ ${ }^{1}$ Shandong Provincial Key Laboratory of Preparation and Measurement of Building Materials, University of Jinan, \\ Jinan 250022, Shandong, P. R. China \\ ${ }^{2}$ School of Materials Science and Engineering, University of Jinan, Jinan 250022, Shandong, P. R. China
}

Received 13 July 2015, received in revised form 18 January 2016, accepted 22 January 2016

\begin{abstract}
Ni60-NB-Ag was firstly used to fabricate composites to increase the wear resistance of TA7 (Ti-5Al-2.5Sn) titanium alloy surface by means of a laser melted deposited (LMD) technique. Experimental results revealed that a large quantity of the interdendritic lamellar eutectics, the nanoscale particles (NP), and the amorphous structure were formed in such composites. During an LMD process, great amounts of Ag were released from the pre-placed layer, which increased the number of the nucleation points, favoring the formation of a fine microstructure and also the NP. However, too high Ag content led the micro-cracks to be produced. Compared with a TA7 substrate, an improvement of the wear resistance was observed for such LMD composites.
\end{abstract}

Key words: metal-matrix composites, surface properties, laser technique, nano-materials

\section{Introduction}

Laser processing technology, such as LMD technique, as a new production route, was applied to prepare the nanocrystals-reinforced composite coating, which can greatly improve the wear resistance of titanium alloys $[1,2]$. Titanium and its alloys have been widely utilized in the aeronautical, chemical, and defense industrial sectors, because of the high specific strength, sufficient stiffness, and outstanding corrosion resistance; nevertheless, the limited wear resistance of $\mathrm{Ti}$ and its alloys is regarded as a significant disadvantage for the application environments involving abrasive and erosive phenomena.

Among recent advances in the formation of excellent performance materials is the concept of the nanocrystalline metals [3, 4]; moreover, in the last decades, nano-composite coatings have become very popular because of their high toughness and stiffness along with their superior hardness, which makes the nano-composite coatings promising candidates in mechanical and tribological applications $[5,6]$. The conventional Ni-based wrought alloys can be categorized into two types, namely, wear resistance alloys and cor- rosion resistance alloys. The wear resistance alloy powder, such as Ni60 is essentially Ni-Cr-B-C-Fe quaternary, with $\mathrm{Cr}$ providing strength and wear resistance to the Ni-rich solid solution, as well as functioning as the chief carbide former during alloy solidification [7]. Through experimental work, it is noted that LMD of the Ni60-NB-Ag mixed powders on a TA7 can form the composites. In this study, the structural evolution and wear performance of the LMD nanocrystalline composites were investigated in detail.

\section{Experimental}

TA7 samples $(10 \mathrm{~mm} \times 10 \mathrm{~mm} \times 35 \mathrm{~mm}$ for wear or $10 \mathrm{~mm} \times 10 \mathrm{~mm} \times 9 \mathrm{~mm}$ for microstructure analysis) were used, and the thickness of pre-placed layer was $0.6 \mathrm{~mm}$, which were polished with $\mathrm{SiC}$ grit paper prior to the coating operation; chemical composition of the TA7 alloy: 5.00Al, 2.50Sn, 0.5Fe, 0.08C, $0.05 \mathrm{~N}, 0.015 \mathrm{H}, 0.2 \mathrm{O}$ and balance $\mathrm{Ti}$; alloy powders of $\mathrm{Ni60}(\geq 99.5 \%$ purity, $100-200 \mu \mathrm{m}), \mathrm{Ag}(\geq 99.5 \%$ purity, $100-200 \mu \mathrm{m})$, and $\mathrm{NB}(\geq 99.5 \%$ purity, 50$200 \mu \mathrm{m})$ were used for LMD, chemical composition

*Corresponding author: tel.: +86-13156193068; e-mail address: jqhup56@163.com 

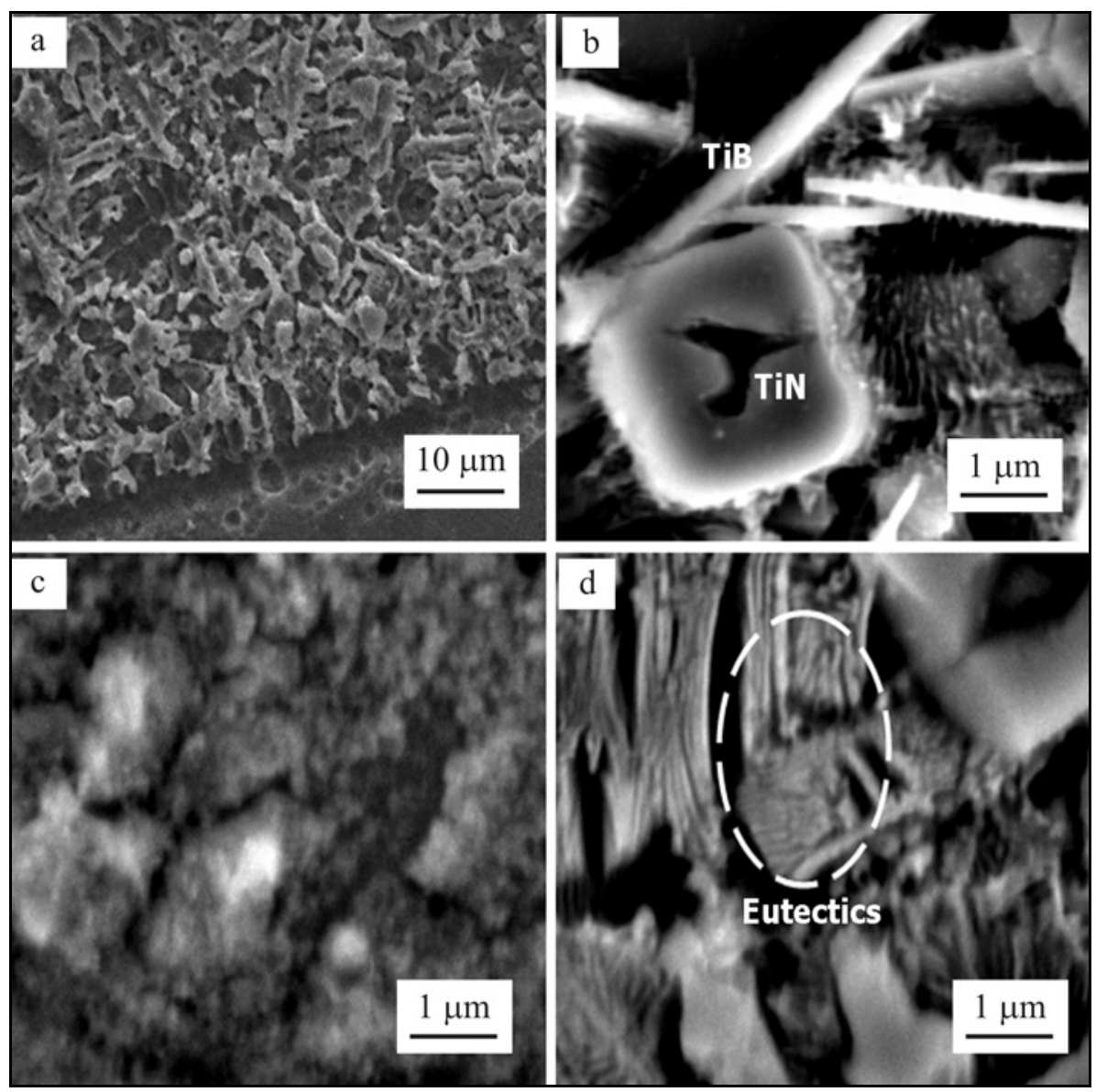

Fig. 1. SEM images of the LMD composites in sample 1: (a) the bond zone, (b) TiB and TiN precipitates, (c) NP, and (d) eutectics.

of $\mathrm{Ni60}$ (wt.\%): $0.8 \mathrm{C}, 15 \mathrm{Cr}, 3 \mathrm{~B}, 4 \mathrm{Si}, 10 \mathrm{Fe}$ and balance $\mathrm{Ni}$; alloying powders (wt.\%): $86 \mathrm{Ni60}-12 \mathrm{NB}-2 \mathrm{Ag}$ (sample 1) and 82Ni60-12NB-6Ag (sample 2). The water glass was used to be the binder. A $5 \mathrm{~kW}$ continuous wave of $\mathrm{CO}_{2}$ laser (HL-T5000) was employed to melt the samples' surfaces. Three-track lap coating was formed on the substrate; the lap rate was approximately $25 \%$ in order to cover a large area uniformly. During the LMD process, the surface oxidation was prevented by an inert gas with the flow rate of $40 \mathrm{~L} \mathrm{~min}^{-1}$, the parameters of an LMD process: laser power of $0.8 \mathrm{~kW}$, scanning speed of $4 \mathrm{~mm} \mathrm{~s}^{-1}$. The LMD samples were polished, then etched in the hydrofluoric acid + nitric acid aqueous solution, and the volume ratio of hydrofluoric acid, nitric acid, and water was $1: 1: 1$.

The wear volume loss was measured after $50 \mathrm{~min}$. Wear resistance of LMD composites was tested by a WMM-W1 disc wear tester, rotational speed of the wear tester was $435 \mathrm{r} \mathrm{min}^{-1}$. The linear velocity of the friction surface was $0.84 \mathrm{~m} \mathrm{~s}^{-1}$; microstructural morphologies of such LMD composites were analyzed by means of an LEO 1525 scanning electron microscope (SEM).

\section{Results and analysis}

\subsection{Microstructure analysis}

As shown in Fig. 1a, there is a metallurgical combination between the LMD composites of sample 1 and substrate, the matrix phases are a solid solution of $\mathrm{Ni}$ with some $\mathrm{Cr}, \mathrm{Si}, \mathrm{N}$, etc., providing the dendritic structures. There are the interdendritic lamellar eutectics made up mainly of $\mathrm{Ni}$ and small amounts of B, Si, etc. As shown in Fig. 1b, the TiB stick-shape, and TiN block-shape precipitates are produced in such layer, which may retard the growth of themselves in a certain extent, favoring the formation of a fine microstructure. The fact that due to the dilution effect of the substrate to the LMD composites, Ti entered in laser molten pool, which reacted with $\mathrm{B}$ and $\mathrm{N}$, forming $\mathrm{TiB}$ and $\mathrm{TiN}$, respectively. It is also noted that a great number of the NP are also produced in such layer (see Fig. 1c). The fact that during the LMD process, lots of Ag were released from the pre-placed layer, which increased the number of the nucleation points, forming a fine structure [8] and also lots of NP [9]. Investigation [10] indicates that $\mathrm{NP}$ usually located on 

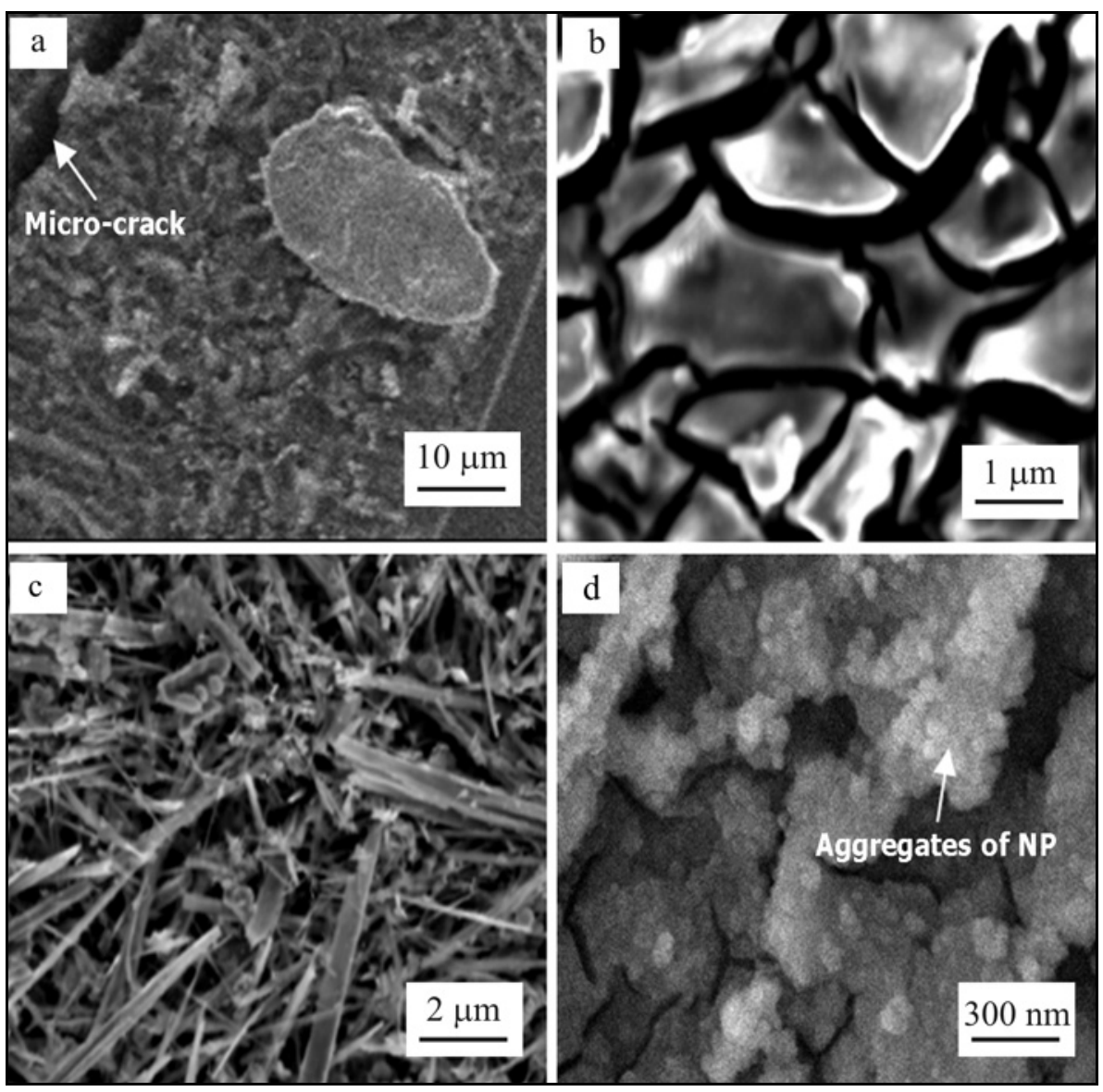

Fig. 2. SEM images of the LMD composites in sample 2: (a) the bond zone, (b) the amorphous bulk, (c) stick-shape and block-shape precipitates, (d) aggregates of NP.

the grain boundaries, which are able to block the motion of the dislocations. The fact that the glass forming alloy composites are close to eutectics implies a relatively low melting point, i.e. the production of the eutectics in such composites promotes the formation of amorphous structure greatly.

As shown in Fig. 2a, the micro-cracks, and unmelted block-shape precipitates were produced in the bond zone between the LMD composites and substrate in sample 2. It was considered that there was a huge difference between the thermal expansion coefficients of the Ag-Ti compounds and $\gamma-(\mathrm{Fe}, \mathrm{Ni})$. Thus, the difference of such thermal expansion coefficients is in direct proportion to the Ag content. Hence, with increasing the $\mathrm{Ag}$ content, the thermal stress caused by the interaction force between temperature gradient and the difference in the thermal expansion coefficients also enhanced accordingly. When the yield strength was exceeded by a thermal stress, the micro-cracks were formed. It was noted that the piece-like amorphous materials were produced in such LMD composites. Also, lots of microcracks were observed (see Fig. 2b). It was speculated that the rapid solidification characteristic of laser molten pool promoted the production of this kind of piece-like materials; more- over, as mentioned previously, Ag promoted the NP to be produced, the production of NP also favored the formation of amorphous structure. It was also noted that a large amount of the fine stick-shape and block-shape precipitates were also produced (see Fig. 2c). Thus, it is known that Ag led a structure of the LMD composites to be fine. As shown in Fig. 2d, the agglomerations of NP were produced, indicating that the NP were easily reunited because of surface effect.

\subsection{Micro-hardness and wear analysis}

Under the action of LMD composites of sample 2, the micro-hardness distribution of the substrate surface was in a range of $1200-1400 \mathrm{HV}_{0.2}$, which was significantly higher than that of the composites in sample 1 (about 900-1000 $\mathrm{HV}_{0.2}$ ), and was approximately 3 times higher than that of TA7 substrate (about 330 $\mathrm{HV}_{0.2}$ ) (see Fig. 3a). It is considered that an enhancement of the micro-hardness of sample 2 was mainly ascribed to the action of the fine grain, solid solution, amorphous structure, and hard phase strengthening. For example, the fine grain strengthening of the Ti-B precipitates, the solid solution strengthening of $\mathrm{Cr}$ and $\mathrm{Si}$ in $\gamma-\mathrm{Co} / \mathrm{Ni}$, the amorphous strengthening of 

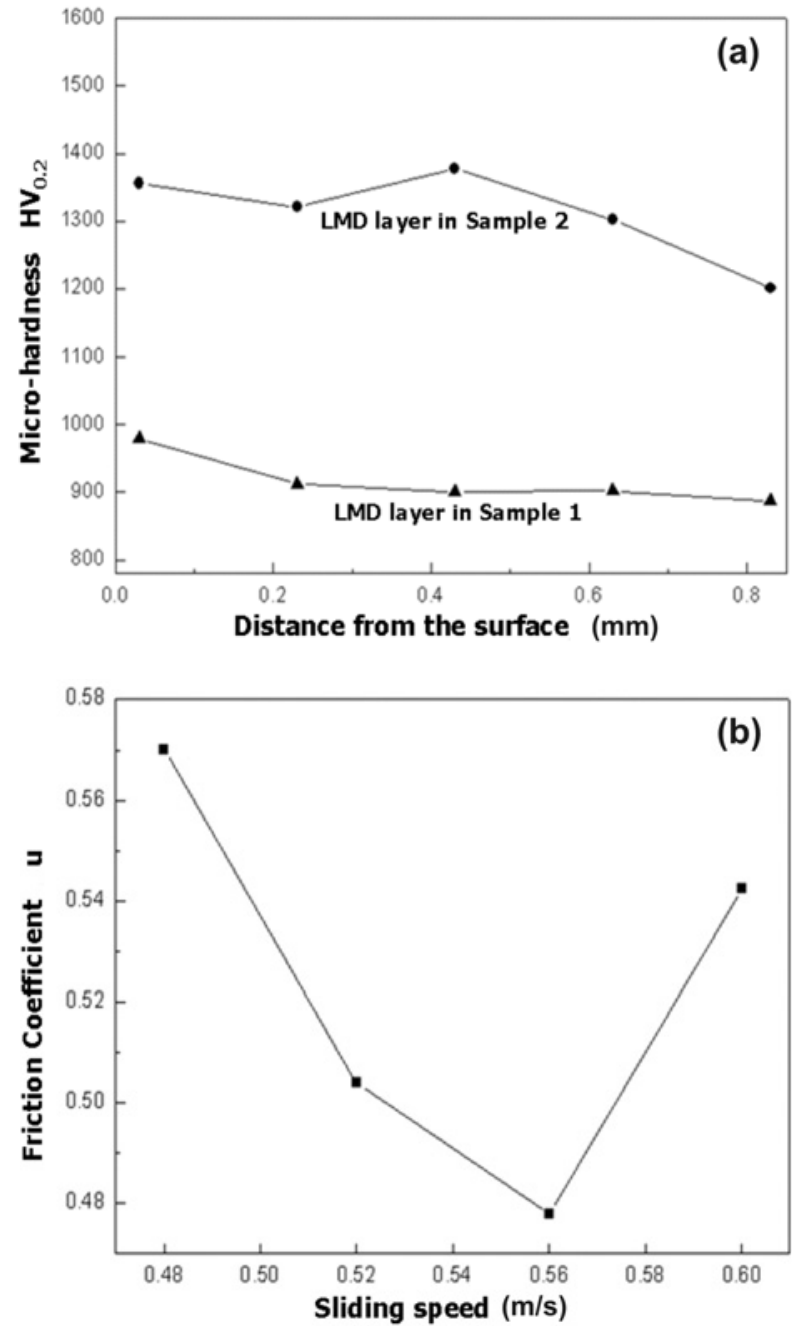

Fig. 3. (a) Micro-hardness distribution of the LMD composites of samples 1 and 2, (b) friction coefficient of sample 1.

the Fe or Si-based amorphous structure, and the hard phases strengthening of NP and the ceramics, such as TiN, etc. all played an important role in increasing the micro-hardness.

Figure $3 \mathrm{~b}$ shows the increase in the friction coefficient of sample 1 from the sliding speed 0.56 to $0.60 \mathrm{~m} \mathrm{~s}^{-1}$ corresponded to an increase in the wear rate. It revealed that the wear behavior of LMD composites was highly dependent on the sliding speed, the resulting LMD composites sliding against counterpart mode were more suitable for tribological applications at moderate sliding speeds of $0.48-0.60 \mathrm{~m} \mathrm{~s}^{-1}$.

As shown in Fig. 4a, a smooth worn surface is obtained in sample 1. It is considered that the formation of the smooth worn surface is mainly ascribed to the action of the fine grain, the solid solution, hard phases and amorphous-nanocrystalline phases. For instance, the fine grain strengthening of the TiN and Ti-B precipitates, the solid solution strengthening of $\mathrm{Cr}$ in
$\gamma$-Co, the amorphous-nanocrystalline phases strengthening of the Fe- or Si-based amorphous phase and the $\mathrm{NP}$, and the hard phases strengthening of the ceramics, etc., all played important roles in improving the wear resistance. Under the action of the pinning effect of the precipitates, the counterpart should overcome the hinders of such fine and dense precipitates, preventing the formation of deep plowing grooves during the dry sliding wear process $[11,12]$.

The worn surface of the composites in sample 2 was characterized by the production of many shallow grooves (see Fig. 4b). Due to the high brittleness of such composites, the hard asperities on the surface of the counterpart can penetrate easily into the sliding surface of sample 2, so the deep grooves and the adhesive features were observed clearly. As shown in Fig. 4c, the amorphous bulks, and the microcracks were also present on the worn surface of sample 2. The counterpart should overcome hinders of the high micro-hardness amorphous structure decreasing the wear volume to a certain extent $[13,14]$. However, the production of micro-cracks favored an increase of the wear volume.

The wear test results indicate that the wear volume loss of a TA7 alloy is significantly higher than that of LMD composites (see Fig. 4d). The moderate growth dispersal nanoscale precipitates may withstand the external normal load better, which showed the excellent properties of the plasticity, wear and toughness, favoring an improvement of the wear resistance $[15,16]$. Although a high content of the amorphous structure in composites of sample 2 decreased the wear volume to a certain extent, the production of micro-cracks was harmful in decreasing the wear resistance; as mentioned previously, the non-uniform microstructure of composites in sample 2 also increased the wear volume loss.

\section{Conclusions}

The LMD technique has provided the important opportunities in the realization of the production of nanocrystalline composites on a TA7 titanium alloy. LMD of the Ni60-NB-Ag mixed powders on a TA7 formed the nanocrystalline composites. During the LMD process, lots of Ag were released from the preplaced layer, which increased the number of the nucleation points, favoring the formation of fine microstructure and also the NP. When the Ag content is 5 wt.\% in the pre-placed layer, the thermal stress caused by the interaction force between temperature gradient and the difference in the thermal expansion coefficients also enhanced greatly. When the yield strength was exceeded by the thermal stress, the micro-cracks were produced, decreasing the wear resistance of such composites. The improvements of wear resistance of 

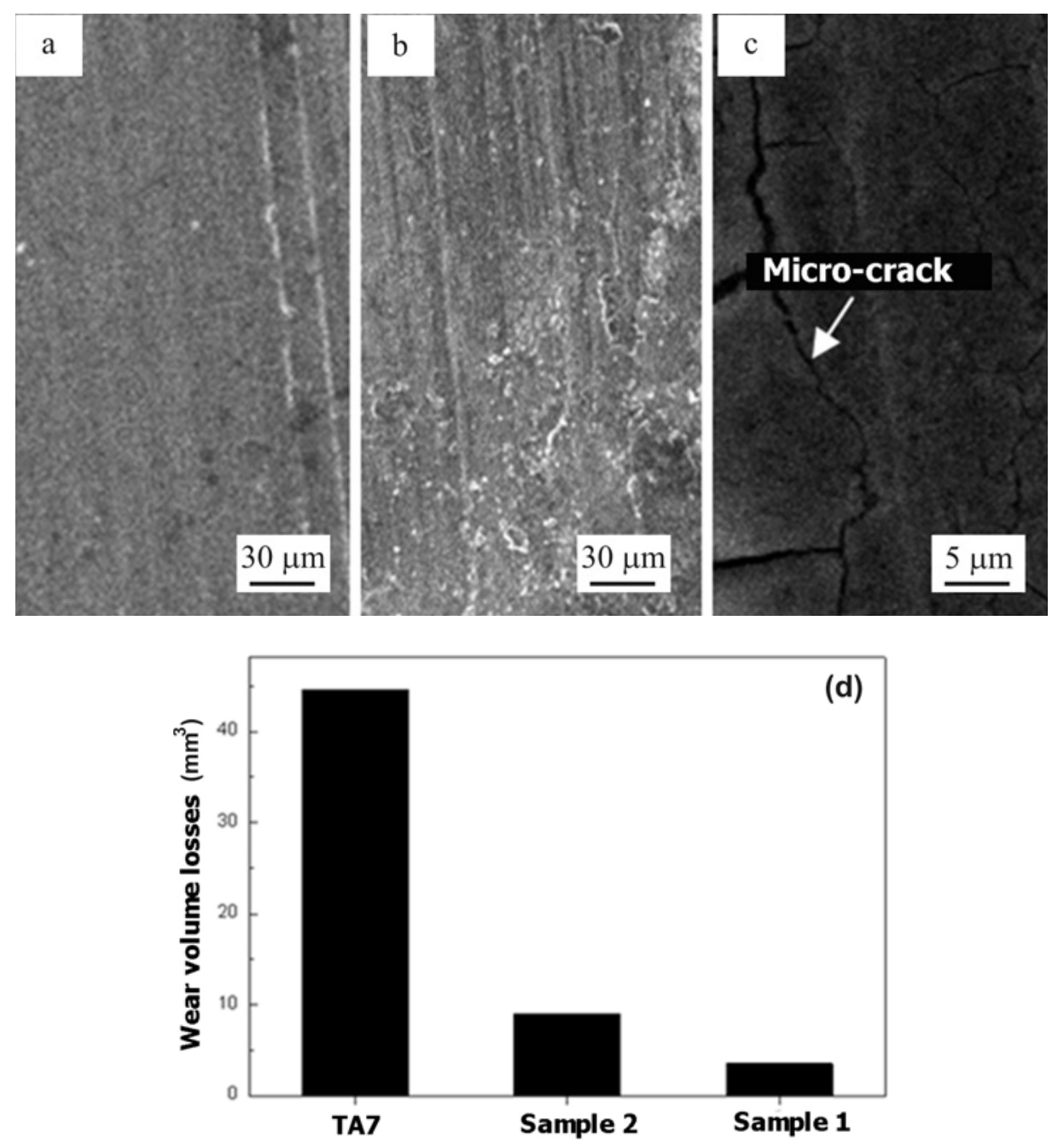

Fig. 4. Worn surface of sample 1 (a) and 2 (b, c); wear volume loss of samples 1, 2 and TA7 alloy (d).

such LMD composites are ascribed mainly to the actions of the fine grain, solid solution, amorphous structure, and hard phase strengthening.

\section{Acknowledgements}

This work was supported by the Natural Science Foundation of China (Grant No. 51373069), the Natural Science Foundation of Shandong Province (Grant No. ZR2016EMM07) and the Doctor Foundation of University of Jinan (Grant No. XBS1305).

\section{References}

[1] Qu, H. P., Wang, H. M.: Mater. Sci. Eng. A, 466, 2007, p. 187. doi:10.1016/j.msea.2007.02.073

[2] Sha, C. K., Lin, J. C., Tsai, H. L.: J. Mater. Process. Technol., 140, 2003, p. 197. doi:10.1016/S0924-0136(03)00713-1

[3] Li, J. N., Yu, H. J., Chen, C. Z., Gong, S. L.: J. Phys. Chem. C, 117, 2013, p. 4568. doi:10.1021/jp311138f
[4] Li, J. Q., Liu, H. S., Li, J. N., Li, G. Z.: Nano, 8, 2013 , p. 1350038. doi:10.1142/S1793292013500380

[5] Chang, L., Zhang, Z., Breidt, C., Friedrich, K.: Wear, 258, 2005, p. 141. doi:10.1016/i.wear.2004.09.005

[6] Taghvaei, A. H., Stoica, M., Khoshkhoo, M. S., Thomas, J., Vaughan, G., Janghorban, K., Eckert, J.: Mater. Chem. Phys., 134, 2012, p. 1214. doi:10.1016/j.matchemphys.2012.04.031

[7] Yao, J. H., Yang, L. J., Li, B., Li, Z. H.: Mater. Des., 83, 2015, p. 26. doi:10.1016/j.matdes.2015.05.087

[8] Gong, S. L., Li, J. N.: Rare Metal Mater. Eng., 42, 2013 - S2, p. 235.

[9] Jing, Y. T., Wang, H., W., Zhao, J., Yi, H., Wang, X. F.: Appl. Surf. Sci., 347, 2015, p. 499. doi:10.1016/i.apsusc.2015.04.127

[10] Li, J. N., Yu, H. J., Chen, C. Z., Li, W.: Kovove Mater., 50, 2012, p. 169.

[11] Du, B. S., Paital, S. P., Dahotre, N. B.: Opt. Lasers Technol., 45, 2013, p. 647. doi:10.1016/i.optlastec.2012.05.017

[12] Cui, C. Y., Cui, X. G., Zhao, Q., Ren, X. D., Zhou, J. Z., Liu, Z., Wang, Y. M.: Mater. Des., 62, 2014, p. 217. doi:10.1016/j.matdes.2014.05.027

[13] Li, J. N., Xia, C. Z., Liu, P., Pan, G. H., Wang, C. 
W.: J. Alloys Compd., 645, 2015, p. 504.

doi:10.1016/i.jallcom.2015.04.222

[14] Gu, D. D., Hagedorn, Y., Meiners, W., Wissenbach, K., Poprawe, R.: Compos. Sci. Technol., 71, 2011, p. 1612. doi:10.1016/j.compscitech.2011.07.010

[15] Matthews, D. T. A., Ocelik, V., de Hosson, J. Th. M..: Mater. Sci. Eng. A, 471, 2007, p. 155. doi:10.1016/j.msea.2007.02.119
[16] Yang, J., Huang, J. H., Fan, D. Y., Chen. S. H.: Mater. Des., 88, 2015, p. 1031. doi:10.1016/j.matdes.2015.09.108 